\title{
A Brief Analysis on Teaching Approach Transition of Engineering Subjects in Terms of Innovation*
}

\author{
Shi weisheng, Zhou mengna, Peng zhen, Liu haimin, Zhang fujie, He yushu \\ Faculty of modern agriculture engineering, kunming university of science and technology, Yunnan
}

\begin{abstract}
Talents cultivation is based on innovation and people-oriented ideology, which helps promote the teaching process being a class interaction. During the actual teaching practice, this ideology enhances the teaching approach renovation of colleges and universities by combing quality education and class teaching together. This thesis applies five thinking methods to realize the innovation of teaching approach.
\end{abstract}

KEYWORD: alent Cultivation; Teaching Approach; Transition

\section{INTRODUCTION}

Innovative talents cultivation is one of the primary tasks of quality education in colleges and universities. It requires a thorough change of talent cultivation mode. The focus of talent cultivation is the transition of teaching approach which is normally of high importance and emphasis[1].

Students are of different characteristics, but of same dignity, passion and dreams. They require knowledge and obtain development. However, teachers are basically the controller of the whole class and the text books are the whole world to the class[2]. Ignoring students' individual development and their initiative affects their actual learning practice. Teaching is a mutual process. Innovation ideology brings the transition of teaching approach and also requires the new way of learning.

Based on the idea of quality education, the focus becomes the enhancement of each individual's inner quality. By various education methods, quality education serves as a tool to transfer the objective knowledge into students' inner and individual quality, in a much stable way. College education process is primarily passing down the objective knowledge to students, but more importantly, it is to help students foster a correct learning approach and ability, and thereby, make them creative and initiative. Therefore, it is critical to combine innovative education and college education, to realize the teaching transformation in colleges and universities. Exploring relative and correct teaching approach for innovative talent cultivation is the main focus of current education transition[3].

\section{TEACHING APPROACH TRANSITION}

During the theoretical teaching process of "productprocessing engineering", we change the traditional teaching logic and teaching method, but apply advanced scientific teaching ideology by combining modern creative education idea and actual teaching content together.

Students' learning process is not about obtaining the conclusions and references in text books, but about joining in the vivid and meaningful thinking activities to experience practice and innovation. Changing their learning style is to abandon the passive and single learning approach, and involve the active and multiple approaches. Therefore, during the teaching process of

"Product-Processing Engineering" we apply below teaching methods, for the purpose of changing learning style and enhancing individual development.

\subsection{Inquiry-based Teaching Method}

Inquiry-based teaching method is to select appropriate teaching material by reasonable teaching target, and to design in-class activities according to

\footnotetext{
* [Project sources]: The education discipline direction of school team project on micropropagation fast (201328).

[Author introduction]: shiweisheng (1964--), man, master, professor. faculty of modern agriculture engineering, kunming university of science and technology. E-mail:shiweisheng888@sina.com
} 
the standard learning process of discovering problems, analyzing problems and solving problems, and to guide students acquiring knowledge and skills by themselves and thereby foster correct value of life.

For instance, in the chapter of "Refrigeration Equipment", "Pressure-control Valve of Piston Compressor" is the teaching focus and emphasis. It involves "overflow valve", "relief valve" and "sequence valve", all with same working principle and mechanical structure, but of different quality and functions. Therefore, teachers should focus on overflow valve, and specifically on its working principle, structure, functions and quality. But when it comes to relief valve and sequence valve, teachers should point out the differences among the 3 valves, help students exploring the similarities and differences in the aspect of working principle, inner structure, installation position, function code and appliance. Comparison, analyses, and conclusion will surely help students better master what they've been taught.

This kind of teaching method is based on exploring problems, and is processed by interaction between teachers and students, and ultimately help foster students a good thinking ability. But when applying this method, we should pay special attention to below respects:

a. Choose proper teaching material, and focus on the teaching purpose. Teachers should stress on the key points and define critical focus, to make students better understand the knowledge and master the skills. b. Define proper problems for students to explore in class. During teaching process, we don't encourage too many questions, too extensive questions, too simple ones, and too obscure ones. The problems explored and the questions raised in class should be single yet right to the teaching aim. c. During the exploring process, teachers should try every method to motivate students to join in class activities, and master the knowledge by themselves.

\subsection{Experiential Teaching Method}

According to proper teaching aim, teachers design students' learning activities by the process of experiencing, communicating and concluding, to help them acquire knowledge and skills actively.

Take the chapter of "Food Packaging Machinery" for instance, when it comes to the working principle of cutting machine, students find it too abstract to understand that cutting depth differs by the cutmaterials. But teachers should help them compare and understand by a specific case in daily life: when cutting watermelon, we don't need to cut thoroughly from one end to the other, but merely to a certain depth where there pops up a sound of crash. Yet when cutting a piece of sugar, you must cut it through to make it split. Hence, when cutting different materials, we cut by different depth.

The feature of Experiential Teaching Method is to let students experience and exercise. But it requires students taking full use of life experience to obtain new knowledge. When applying this teaching method, you need to pay attention to below aspects.

a. The scenarios and materials should be about learning target, and should be close to students' life experience, and should serve as a kind of motivation to help students better acquire the new knowledge. $b$. Teachers should guide students experience and conclude by themselves. And the process should be in accordance with the common law of recognition. c. Teachers should be observant at the students thinking logic as well as their innovation.

\subsection{Practice-based Teaching Method}

Aiming at learning purpose, and starting from actual practice, teachers should guide the students put the textbook knowledge into practice. The focus is to foster student ability, and the method is suitable to all experimental classes, and research-kind of learning.

Take "Hydraulic Control System" teaching for instance, it appears much noise and vibration from hydraulic pump when power on. This is when students analyze and solve the issue. Through a comparison to normal operation process of hydraulic pump, students can figure out the reason and solution: Firstly, There involves air. The solution should be prompt examination of pipeline, seal situation and the height of liquid level. Secondly, it applies excessive rotational speed. The solution is properly lowering the rotational speed. Thereby the whole hydraulic system recovered normal working process promptly.

When applying such learning method, we should focus on below aspects:

a. Establish learning goals. Teachers should guide the students better master the operation procedure, method, and skills. b. Teach students the ability of sharp observance during operation process, and the ability of analysis. We should combine practice ability and think ability together; and we should also foster creative ability at the same time.

\subsection{Teach and Practice-Integrated Teaching Method}

This is a teaching method that involves teaching, learning and practicing. After defining basic terms mentioned in text books and the components of processing machinery parts, teachers should guide student process with analysis of mechanical 
operation methods by indicating the working principle of each parts. This method can not only motivate the students, but also make the teaching process vivid and interesting. If teachers follow the process of "teaching by books, assign homework by books, and assess student ability via various tests", students could easily lose interest. Therefore, Teach and Practice-Integrated Teaching Method is especially available for teaching of "Agricultural Products Processing" and other subjects related.

\subsection{Error-analysis Teaching Method}

While teaching students of frequently occurred problems of perception or errors during the process of operation, teachers should specify the problems that occur to most students in the parts. For instance, in the chapter of "Heat Transfer Equipment", heat input is the topic where problems turn up mostly. Letting students discuss and explore whether heat should come from upper end or lower end can easily motivate them. This kind of teaching method requires teacher to accumulate teaching and practicing experience.

\section{TRANSITION OF ACTUAL TEACHING}

According to the specific characteristics of our national education situation, teaching practice should be changed before trying changing students' learning method, i.e. a transition to "class-interaction". Based on the fact that teaching is to enhance students' individual development, teaching practice should be changed from below aspects:

\subsection{A Change of Role}

This requires a teacher changing the role of teaching into the role of promoting, to promote students actively observe, analyze, explore, research, and conclude all by themselves. As teachers, we should try our best to offer them an easy, free and equal atmosphere in class, and give them support and encouragement by proper means, to make students thinking actively and logically.

\subsection{A Change of Teaching Practice}

While setting teaching goals before class, teachers should emphasize students' development, instead of obtaining merely what's in the books. We should focus on letting students know "How" instead of just knowing "What". Students should be led to form the thinking mode of "Observe-Conclude-Practice". As to teaching approach, teachers should take full use of information, and make the class interaction a more effective way to pass down the knowledge.

\subsection{A Change of Perception}

To change the traditional perception of teaching and the role in the teaching process, teachers should establish below ideology:

a. Teaching Course: Teaching course is not merely "text books" (teaching plan, teaching syllabus, text books, and lesson plans). It is not a carrier of specific knowledge, but a mutual process between teachers and students to explore knowledge. Teaching process in class is not a process passing down knowledge, but a "dialogue" between text book and "teachers and students". b. Teaching Practice: Teaching is not passing down what teachers know, but communicating with students. It is a mutual process. Teachers should maintain harmonious and free teaching surroundings, and students should tap their potentials. c. Teaching Goal: Teaching goal is no more passing down knowledge, but a combination among knowledge and skills, teaching process and methods, and teaching/learning attitude and values, to emphasize the focus of individual development.

\section{APPLY 5 THINKING METHODS AND REALIZE RENOVATION OF TEACHING APPROACH}

1. Inspire thoughts by questions, and enhance teaching efficiency. According to teaching content and college students' features, teachers should use more questions to inspire thoughts. It can let students obtain knowledge and skills in a vivid way, but also promote the students theoretically.

2. Inspire thoughts by interaction in class. Having seminars among students and teachers, and discussing teaching, learning and research, can help motivate students and let teachers know more about students, and ultimately make progress together.

3. Inspire thoughts by encouraging changes. This is to enhance students apply creative thinking style. Learning is for developing. Inspire thoughts by encouraging changes is actually encouraging students using creative thinking logic.

4. Inspire thoughts by quoting examples. This is to focus on teaching efficiency and teaching result. Conclude on good examples and form theoretical understandings; Learn from problems and explore solutions. It can help motivate the ability of solving problems, as well as enhancing understanding of creation.

5. Inspire thoughts with "key problems", to maintain students' interest and ideology of creation. 


\section{REFERENCES}

[1] Tang Xiaoliang, The Teaching $M$ ode and Innovation of Software Engineering UnderNew Development Opportunities, Computer CD Software and Application, 2011, (17): 242-242.
[2] Jin wei zu, pan lu, huang jie , Application of CDIO Education Concept in Curriculum Design, Computer Education,2010,(11):120-122.

[3] Liu Jun-hong, wang Fu-mei, liu Rui-fan, Application of STS theory in the teaching of fermentation engineering, LABOR A TORY SCIENCE, 2011, 14(6): 46-48. 